\title{
Comparative Accuracy of Panoramic Radiograph and Cone- beam Computed Tomography Images in Identification and Measurement of the Anterior Loop of Mental Nerve: A Meta- analysis and Review of the Literature
}

\author{
Shubhabrata Roy ${ }^{1}$, Deepa Raj², Soumitra Ghosh ${ }^{3}$, Sayan Majumdar ${ }^{4}$, Samiran Das ${ }^{5}$
}

\begin{abstract}
Aim and objective: This study aimed to assess the relative accuracy of two-dimensional panoramic radiographs compared with three-dimensional computed tomography (CBCT) images for identification and measurement of the anterior loop of the mental nerve.

Materials and methods: The study was about to determine the comparative diagnostic accuracy of panoramic radiograph and cone-beam computed tomography and the study protocol was set according to Preferred Reporting Items for Systematic Reviews and Meta-Analyses (PRISMA) diagnostic test accuracy guideline. The search was limited to English literature only and included an electronic search through PubMed and Google Scholar databases. The search was further complemented by extensive hand-searching. All studies published up to November 2019 were included (without any starting limit). Two independent investigators extracted the data and assessed the studies based on the inclusion and exclusion criteria.

Results: Out of the initial 308 records, only 4 studies were included in this review for qualitative data synthesis. The quality assessment of included studies was done through QUADAS-2. Quantitative data synthesis was done to compare the relative accuracy of two-dimensional radiographs compared with three-dimensional scans from three out of the four selected articles. Statistical analysis was done with the help of Meta-DiSc version 1.4. The pooled sensitivity of panoramic radiography was 0.45 (Cl 95\%: $0.34-0.56$ ) and pooled specificity was 0.75 (Cl 95\%: 0.69-0.80). In the symmetric summary receiver operating characteristic (SROC) plot, the area under the curve (AUC) was 0.8832 , and $Q^{*}$ was 0.8137 .

Conclusion: Compared with cone-beam computed tomography (CBCT) images as the gold standard reference test, two-dimensional panoramic radiographs showed lower sensitivity and reasonable specificity. It is clear from the SROC curve that panoramic radiography can be used for the identification of the anterior loops. Still, it is better to avoid it as an alternative to three-dimensional scans to determine the presence and extension of the anterior loop of the mental nerve because of the tendency toward low sensitivity and over or under-estimation of the length. Keywords: Anterior loop, Cone-beam computed tomography, Inferior alveolar nerve, Mental nerve, Panoramic radiograph. International Journal of Prosthodontics and Restorative Dentistry (2021): 10.5005/jp-journals-10019-1322
\end{abstract}

\section{INTRODUCTION}

After entering the mandible at the mandibular foramen, the inferior alveolar neurovascular bundle extends anteriorly through the mandibular canal and then gets divided into two parts (the mental and incisive branches)., ${ }^{1,2}$ The mental nerve supplies sensation to the skin and mucous membrane of the lower lip, chin, and the vestibular gingiva of the mandibular anterior teeth, while the incisive branch innervates the anterior teeth including the first premolar. ${ }^{2,3}$

The anterior loop can be described as that part of the mental neurovascular bundle where the mental neurovascular bundle crosses inferior and anterior to the mental foramen only to loop back to exit the mental foramen. ' Sufficient precautions should be taken by a clinician during any surgical procedure in the lower premolar region to prevent direct or indirect injury to the neurovascular bundle. ${ }^{4}$ Many authors have proposed to maintain a pre-determined fixed safe distance mesially from the mental foramen for placement of an endosseous implant or to perform osteotomy surgeries. ${ }^{5,6}$ Still, it is always advisable to confirm the presence and length of the anterior loop of mental nerve in radiographs before any surgical intervention as wide variations in prevalence and length have been reported in several studies.

Although three-dimensional diagnostic imaging modalities like cone-beam computed tomography are more or less comparable to
1,3-5 Department of Prosthodontics and Crown and Bridge, Guru Nanak Institute of Dental Science and Research, Kolkata, West Bengal, India

${ }^{2}$ Clinical Practitioner, Kolkata, West Bengal, India

Corresponding Author: Shubhabrata Roy, Department of Prosthodontics and Crown and Bridge, Guru Nanak Institute of Dental Science and Research, Kolkata, West Bengal, India, Phone: +91 8582879201, e-mail: bios83roy@gmail.com

How to cite this article: Roy S, Raj D, Ghosh S, et al. Comparative Accuracy of Panoramic Radiograph and Cone-beam Computed Tomography Images in Identification and Measurement of the Anterior Loop of Mental Nerve: A Meta-analysis and Review of the Literature. Int J Prosthodont Restor Dent 2021;11(3):132-137.

Source of support: Nil

Conflict of interest: None

direct physical measurements of any anatomical structure in terms of accuracy, the intraoral periapical and the panoramic radiographs are the most commonly used imaging modalities for diagnosis and treatment planning in dentistry. ${ }^{4,7}$

This article has analyzed the relative accuracy of twodimensional panoramic radiography compared with threedimensional imaging technique like cone-beam computed

(c) The Author(s). 2021 Open Access This article is distributed under the terms of the Creative Commons Attribution 4.0 International License (https://creativecommons. org/licenses/by-nc/4.0/), which permits unrestricted use, distribution, and non-commercial reproduction in any medium, provided you give appropriate credit to the original author(s) and the source, provide a link to the Creative Commons license, and indicate if changes were made. The Creative Commons Public Domain Dedication waiver (http://creativecommons.org/publicdomain/zero/1.0/) applies to the data made available in this article, unless otherwise stated. 
tomography $(\mathrm{CBCT})$ for identification and measurement of the anterior loop of the mental nerve. The purpose of this study was to find out whether two-dimensional images like panoramic radiographs can be used as an alternative to cone-beam computed tomography during the treatment planning for any surgical intervention in the lower premolar region.

\section{Materials and Methods}

The study was conducted as per the 27-item Preferred Reporting Items for Systematic Reviews and Meta-analyses (PRISMA) diagnostic test accuracy checklist. ${ }^{8}$

The primary research question was formed according to the PIRD format for clinical questions:

- Population: Dentulous/partially edentulous/completely edentulous male and female patients or human cadaver.

- Index test: Panoramic radiography.

- Reference test: Cone-beam computed tomography.

- Diagnosis of interest: Relative accuracy of panoramic radiographs in identification and measurement of the anterior loop of mental nerve.

\section{Research Question}

What is the relative diagnostic accuracy of two-dimensional panoramic radiography compared with cone-beam computed tomography in the identification and measurement of the anterior loop of the mental nerve?

\section{Study Design}

This systematic review only included prospective and retrospective studies.

\section{Search Strategy}

Two electronic databases were searched: PubMed and Google Scholar. It was later complemented by extensive manual searching. The systematic review was based on the papers published up to November 30, 2019, without any starting limit. Only articles written in English were considered. The literature search was performed by two independent reviewers (SR and DR). Interrater reliability was determined through Cohen's kappa value (\% of agreement: $83.73 \%$, Cohen's $k$ : 0.67). Disagreements between reviewers were solved through discussions. The search strategy has been presented in Flowchart 1.

Following Medical Subject Headings (MeSH) and Boolean operators were used for data searching:

Inferior alveolar nerve; Anterior loop of mental nerve; Anterior loop AND mental nerve; Anterior loop AND inferior alveolar nerve; Mental nerve AND CBCT; Mental nerve AND panoramic radiographs; Mental nerve AND cadaver studies; Mental foramen AND implant; Three-dimensional radiographic technique AND anterior loop of mental nerve.

\section{Inclusion Criteria}

- Only the comparative studies which compared panoramic radiographs with cone-beam computed tomography for identification and measurement of the anterior loop of mental nerve.

- All samples should be examined and measured by both the index test and reference test in any particular study.

- The studies should provide sufficient data related to the procedures and outcome reports.

\section{Exclusion Criteria}

- Individual case reports, letters, literature reviews.

- Non-English literatures.

- Unclear sample size and sample characteristics.

- Insufficient data.

\section{Data Synthesis and Meta-analysis}

Out of a total of 308 records retrieved through electronic and manual searches, only 53 were selected for complete text review by two independent reviewers (SR and DR). Only four articles ${ }^{9-12}$ fulfilled all the inclusion criteria to be included in the present study.

Three reviewers (SR, DR, and SD) independently extracted the following data (wherever available) from the selected studies: authors, year of study, study population, sampling procedure, sample size, study design, inclusion and exclusion criteria, methods of examination, index test, reference test, outcomes, and limitations.

Pooled sensitivity and a pooled specificity of the selected studies were determined first. Then, the summary receiver operating characteristic (SROC) curve was drawn and the area under the curve (AUC) was measured.

\section{Results}

Out of 53 full-text articles, only 4 articles fulfilled all the inclusion criteria [Vujanovic-Eskenazi et al., Couto-Filho et al., de Brito et al., Kastala et al.]. Out of the 49 rejected articles, 39 used a single diagnostic method, in 2 articles, not all the samples were examined by different methods, 4 articles presented insufficient data, 2 articles compared panoramic radiographs with direct physical measurements, 1 article compared panoramic radiographs with spiral $\mathrm{CT}$, and 1 article compared CBCT with direct physical measurements. A summary of the selected studies has been presented in Table 1.

Risk of bias assessment and applicability of the selected studies was done by The Quality Assessment of Studies of Diagnostic Accuracy-2 (QUADAS-2) ${ }^{13}$ and presented in Table 2.

\section{Meta-analysis}

Quantitative data synthesis was done from three out of the four selected articles. Analysis was performed using Meta-Disc: Version 1.4 software. The forest plots and symmetric SROC curve are presented in Figures 1 to $3 .^{14,15}$ The pooled sensitivity of panoramic radiography was $0.45(\mathrm{Cl} 95 \%: 0.34-0.56)$ and pooled specificity was 0.75 (CI 95\%: 0.69-0.80). In the symmetric SROC plot, AUC was 0.8832 , and $Q^{*}=0.8137$.

\section{Discussion}

The prevalence of the anterior loop of the mental nerve may vary from 0 to $94 \%$ and the length of the anterior loop of the mental nerve can be as long as $11 \mathrm{~mm} .^{2,16,17}$ These wide ranges of variations may be due to individual anatomic variations, different racial stocks, the difference in age and sex of the study populations, use of different measurement techniques and study protocols. ${ }^{2,7}$

Presence of anterior means that the mental nerve traversed inferiorly past the mental foramen and then looped superiorly and distally to emerge from the foramen. ${ }^{2}$ Padmanabhan et al. ${ }^{18}$ conducted a meta-analysis on the incidence of neurosensory disturbance in mandibular implant surgery and concluded that the patients who undergo mandibular implant placement presented 
Flowchart 1: Search strategy

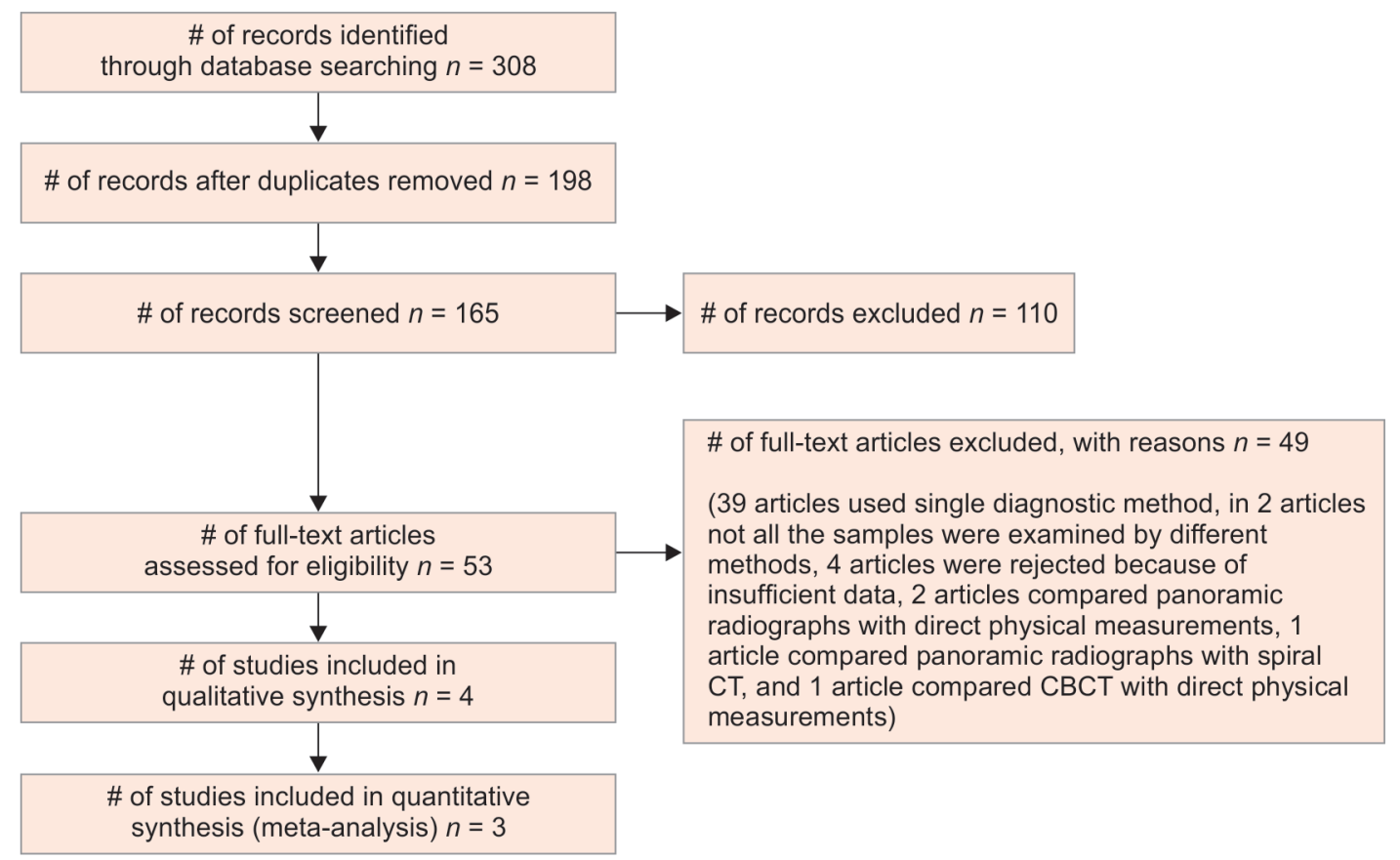

Table 1: Summary of the selected studies

\begin{tabular}{|c|c|c|c|c|c|}
\hline Author (year of study) & Sample size & Imaging modality & Prevalence & Mean length of $A L$ & Maximum length $A L$ \\
\hline \multirow[t]{2}{*}{$\begin{array}{l}\text { Vujanovic-Eskenazi } \\
\text { et al. (2015) }\end{array}$} & $\begin{array}{l}82 \text { patients: age } 18-80 \\
\text { years (mean } 56 \text { years) }\end{array}$ & $\begin{array}{l}\text { Panoramic radiography } \\
\text { (PR) }\end{array}$ & 36.6 & $2.82 \pm 0.91 \mathrm{~mm}$ & $4.7 \mathrm{~mm}$ \\
\hline & & $\begin{array}{l}\text { Cone-bean computer } \\
\text { tomography }(\mathrm{CBCT})\end{array}$ & 48.8 & $1.59 \pm 0.53 \mathrm{~mm}$ & $4 \mathrm{~mm}$ \\
\hline \multirow[t]{2}{*}{$\begin{array}{l}\text { Couto-Filho et al. } \\
(2015)\end{array}$} & $\begin{array}{l}47 \text { patients: age } 18-52 \\
\text { years (mean age } 35 \\
\text { years) }\end{array}$ & $\begin{array}{l}\text { Panoramic radiography } \\
(\mathrm{PR})\end{array}$ & 42.6 & $x$ & $x$ \\
\hline & & $\begin{array}{l}\text { Cone-bean computer } \\
\text { tomography }(\mathrm{CBCT})\end{array}$ & 29.8 & $x$ & $x$ \\
\hline \multirow[t]{2}{*}{ de Brito et al. (2016) } & $\begin{array}{l}90 \text { patients ( } 180 \text { sides): } \\
\text { age } 15-76 \text { years; (mean } \\
\text { age } 26.3 \text { years) }\end{array}$ & $\begin{array}{l}\text { Panoramic radiography } \\
\text { (PR) }\end{array}$ & 22.22 & \multicolumn{2}{|c|}{$\begin{array}{l}\mathrm{X} \text { (data considering the mesial length of the } \\
\text { structures from the mental foramen which in- } \\
\text { cludes both the anterior loop and incisive canal }\end{array}$} \\
\hline & & $\begin{array}{l}\text { Cone-bean computer } \\
\text { tomography }(\mathrm{CBCT})\end{array}$ & 14.3 & & \\
\hline \multirow[t]{2}{*}{ Kastala et al. (2019) } & $\begin{array}{l}90 \text { patients ( } 180 \text { sides): } \\
\text { age above } 18 \text { years }\end{array}$ & $\begin{array}{l}\text { Panoramic radiography } \\
\text { (PR) }\end{array}$ & 37.2 & $\mathrm{X}$ & $8.2 \mathrm{~mm}$ \\
\hline & & $\begin{array}{l}\text { Cone-bean computer } \\
\text { tomography }(\mathrm{CBCT})\end{array}$ & 56.67 & $x$ & \\
\hline
\end{tabular}

Table 2: Risk of bias assessment and applicability of the selected studies

\begin{tabular}{|c|c|c|c|c|c|c|c|}
\hline \multirow[b]{2}{*}{ Study } & \multicolumn{4}{|c|}{ Risk of bias } & \multicolumn{3}{|c|}{ Applicability concerns } \\
\hline & Patient selection & Index test & Reference standard & Flow and timing & Patient selection & Index test & Reference standard \\
\hline $\begin{array}{l}\text { Couto-Filho } \\
\text { et al. (2015) }\end{array}$ & (); & ;) & (;) & ;) & (;) & ;) & (;) \\
\hline $\begin{array}{l}\text { Vujanovic-Eskenazi } \\
\text { et al. (2015) }\end{array}$ & (;) & $?$ & $?$ & (;) & (;) & ;) & (;) \\
\hline $\begin{array}{l}\text { de Brito et al. } \\
\text { (2016) }\end{array}$ & (;) & $?$ & $?$ & (;) & (;) & (:) & (;) \\
\hline Kastala et al. (2019) & + & $?$ & $?$ & $+;$ & $+;$ & $+;$ & + \\
\hline
\end{tabular}

(-)Low risk; : High risk; ? Unclear risk 


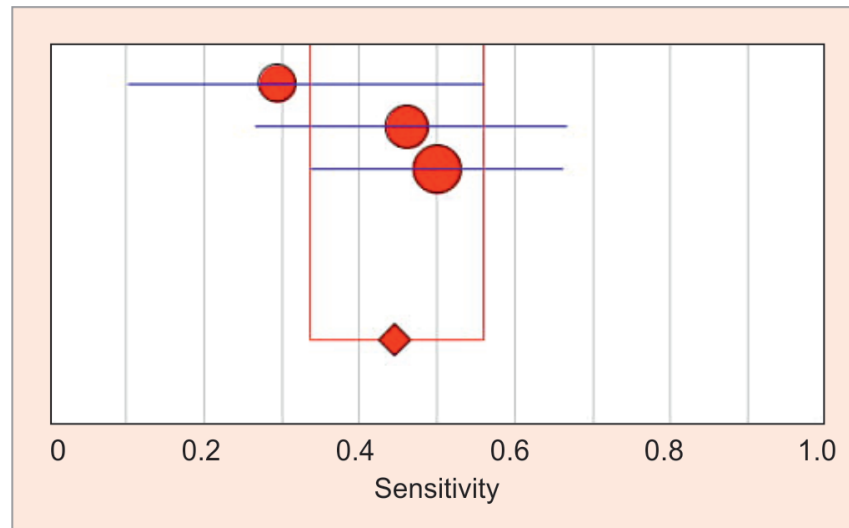

Fig. 1: Pooled sensitivity

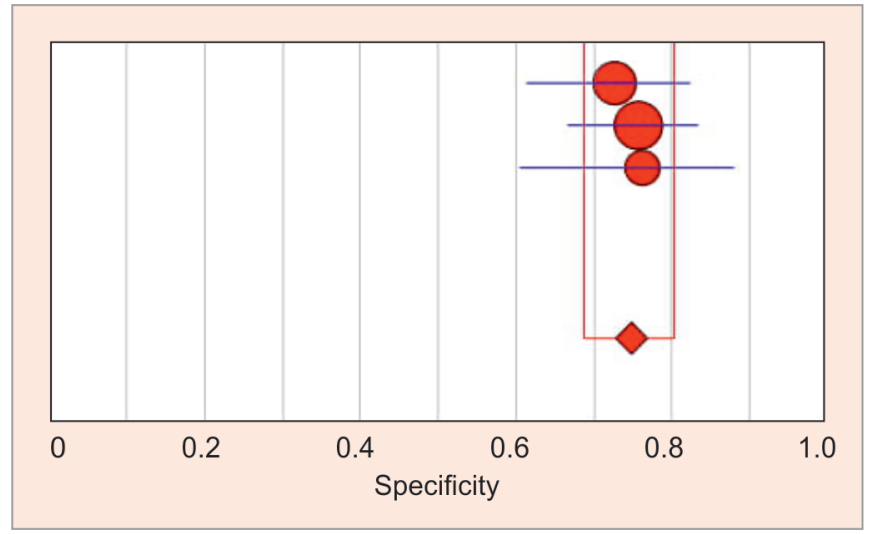

Fig. 2: Pooled specificity

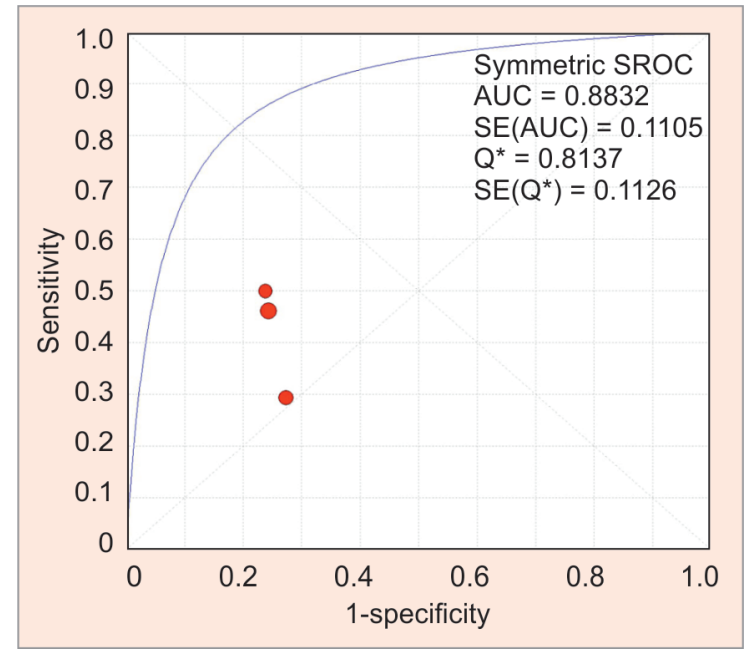

Fig. 3: SROC plot

with a considerably high risk of nerve damage and consequently sensory disturbance. They recommended that the clinicians must take all necessary precautions to avoid such complications.

Although maintaining about $4-6 \mathrm{~mm}$ of safe distance anterior to the mental foramen is frequently recommended in the literature, $, 5,6,19-21$ a universal fixed safe distance may not be an evidence-based solution. Because of the huge variations in the frequency, anatomy, and length, a radiographic diagnostic
Couto-Filho 2015

0.29

$(0.10-0.56)$

de Brito 2016

Vujanovic-Eskenazi 2015

$(0.27-0.67)$

$(0.34-0.66)$

Pooled Sensitivity $=0.45(0.34$ to 0.56$)$

Chi-square $=2.15 ; \mathrm{df}=2(\mathrm{p}=0.3420)$

Inconsistency (I-square) $=6.8 \%$
Specificity $(95 \% \mathrm{Cl})$

$0.73 \quad(0.61-0.82)$

$0.76 \quad(0.67-0.83)$

$0.76 \quad(0.61-0.88)$

Vujanovic-Eskenazi 2015

\begin{abstract}
Pooled Specificity $=0.75(0.69$ to 0.80$)$
Chi-square $=0.26 ; \mathrm{df}=2(\mathrm{p}=0.8774)$
Inconsistency $(\mathrm{I}$-square $)=0.0 \%$
Pooled Specificity $=0.75(0.69$ to 0.80$)$
Chi-square $=0.26 ; d f=2(p=0.8774)$
Inconsistency $($ (I-square $)=0.0 \%$

Pooled Specificity $=0.75(0.69$ to 0.80$)$
Chi-square= $0.26 ; d f=2(p=0.8774)$
Inconsistency $($ I-square $)=0.0 \%$
\end{abstract}

Couto-Filho 2015

de Brito 2016 evaluation is advisable before any surgical intervention at or near the mandibular premolar region.

Physical examination following anatomic dissection is the most accurate method. Still one has to rely on radiographs for pretreatment diagnostic evaluation of the anterior loop of mental nerve in a patient. Panoramic radiograph is a very common diagnostic aid in regular dental practice. Some authors claim that two-dimensional radiographs can be enough for pre-surgical treatment planning for implant placement. Even many studies have estimated the prevalence and length of the anterior loop of mental nerve based on panoramic radiographs.

It is an obvious fact that a three-dimensional image is much more desirable and accurate than a two-dimensional image and can be considered as a gold standard. ${ }^{21}$ Image overlapping and bone density around the bony canals may affect the visualization of structures in two-dimensional radiographs. Three-dimensional scans are also able to overcome this problem as they can visualize a structure in different planes and even can determine bone density.

Computerized tomography provides reliable data through a three-dimensional view and bone density analysis. CBCT is another advanced digital imaging technique that requires a much less radiation dose than the multi-slice CT scan and is capable to reconstruct a 3D image. ${ }^{2}$ A 2010 study (Naitoh et al. ${ }^{22}$ ) presented that 28 CBCT and 28 multi-slice CT images were consistent with each other while tracing the neurovascular structures of the mandible. Therefore, $\mathrm{CBCT}$ can be considered an extremely efficient diagnostic aid. 
The accuracy between $\mathrm{CBCT}$ and direct physical measurement is also acceptable and reliable. Luangchana et al. ${ }^{23}$ evaluated 48 regions of 6 dry human skulls and reported that the mean difference between image measurement and physical measurement was only $-1.06 \pm 1.0$ to $-1.23 \pm 0.81 \mathrm{~mm}$ for maxillary CBCT images and $-0.24 \pm 0.46$ to $-0.55 \pm 0.61 \mathrm{~mm}$ for mandibular CBCT images. The study also revealed that $\mathrm{CBCT}$ of dry mandibles using voxel sizes of $0.2,0.25,0.3$, and $0.4 \mathrm{~mm}$ reported no statistical difference between the image measurements and direct measurements with a digital caliper.

But if the accuracy of a two-dimensional radiographic image is found to be satisfactorily acceptable when compared with the gold standard for a specific diagnostic purpose, then that twodimensional radiograph can be also employed as an economic alternative to a three-dimensional scan.

The quantitative analysis excluded all the cases which were diagnosed as difficult to interpret with either panoramic radiography or three-dimensional scan. The pooled sensitivity of panoramic radiography was 0.45 ( $\mathrm{Cl} 95 \%$ : $0.34-0.56)$ and pooled specificity was 0.75 ( $\mathrm{Cl} 95 \%$ : $0.69-0.80)$. In the symmetric SROC plot, AUC was 0.8832 , and $Q^{*}=0.8137$. It clearly shows that though the panoramic radiographs are reliable to identify the true negative cases, they show a high rate of false-positive results. This result is consistent with the earlier studies. Kastala et al. ${ }^{12}$ concluded that assessing anterior loops with panoramic radiography may present more false-positive results. Couto-Filho et al. ${ }^{10}$ also concluded that panoramic radiographs led to a falsepositive diagnosis of the AL.

No statistically significant difference was found in the anterior loop length between the CBCT (both with and without tracer) and anatomic measurements by Santana et al. ${ }^{24}$ Mardinger et al. ${ }^{25}$ reported that $40 \%$ of the radiographically diagnosed loops were false-positive and there was an over-estimation of the mean length of the anterior loop in periapical radiographs compared with direct physical measurements. Kuzmanovic et al. ${ }^{26}$ also found either over or underestimated the length of the anterior loop of mental nerve in all panoramic radiographs compared with direct measurements. Kaya et al. ${ }^{7}$ presented that the length of the mental loop was $0.71 \pm 0.21 \mathrm{~mm}$ greater in the panoramic radiographs than the spiral computed tomography (SCT) images $(p=0.014)$. An overestimation of mental loop length was evident in all bone qualities on the panoramic radiographs when compared with SCT. The highest overestimation was seen in type IV bone $(1.11 \pm 0.52 \mathrm{~mm}, p=0.01)$, the lowest in type I $(0.22 \pm 0.25 \mathrm{~mm}, p>0.05)$. Kastala et al. ${ }^{12}$ measured both anterior and caudal extensions of the anterior loop of the mental nerve and reported higher mean values in CBCT compared with digital panoramic radiography. Vujanovic-Eskenazi et al. ${ }^{9}$ also reported over-estimation of length with panoramic radiography compared with CBCT. de Brito et al. ${ }^{11}$ have reported that the panoramic radiographic images underestimated the distances by a mean of $2.0 \mathrm{~mm}$ (statistically significant) compared with CBCT. Hence, over or under-estimation of the length of the anterior loop is a common drawback of panoramic radiographs. ${ }^{27}$

Kuzmanovic et al. ${ }^{26}$ showed a negative correlation between both the bone quality and quantity and the radiographic extent of the anterior loop. Kaya et al. ${ }^{7}$ determined the bone quality from the cross-sectional images of the SCT according to the Lekholm and Zarb classification. In all bone qualities, there was an overestimation in mental loop measurements on the panoramic radiographs when compared with SCT. The highest overestimation was seen in type IV bone (1.11 $\pm 0.52 \mathrm{~mm}, p=0.01)$, the lowest in type I $(0.22 \pm 0.25$ $\mathrm{mm}, p>0.05)$. But Vujanovic-Eskenazi et al. ${ }^{9}$ reported that the bone quality did not produce any statistically significant difference for the identification of the mental loop. More studies are required to understand the effect of bone quality on the diagnostic accuracy of different radiographs.

In a systematic review and meta-analysis, Mishra et al. ${ }^{28}$ highly recommended not to rely on any average values and the clinician should compulsorily make use of imaging modalities available in each and every case, wherever surgical procedure is to be performed near the mental foramen region. Therefore, diagnostic aids are mandatory and from the above discussion, we can conclude that three-dimensional radiographic techniques are invariably required for predictable treatment planning.

Although there are many available studies on the frequency and length of the anterior loop of the mental nerve, very few studies have compared the accuracy of different radiographic techniques. The present study clearly shows that there is a scope and need for further studies on the diagnostic accuracy of panoramic radiographs compared with three-dimensional scans.

\section{ConClusion}

Compared with three-dimensional cone-beam computed tomography as the gold standard reference test, two-dimensional panoramic radiographs showed low sensitivity and reasonable specificity. It is clear from the SROC curve that panoramic radiography can be used as a diagnostic imaging modality. Still, it is better to avoid it as an alternative to three-dimensional scans to determine the presence and extension of the anterior loop of the mental nerve because of the tendency of low sensitivity and over or under-estimation of the length.

\section{References}

1. Bavitz JB, Harn SD, Hansen CA, et al. An anatomical study of mental neurovascular bundle-implant relationships. Int J Oral Maxillofac Implants 1993;8(5):563-567.

2. Greenstein G, Tarnow D. The mental foramen and nerve: clinical and anatomical factors related to dental implant placement: a literature review. J Periodontol 2006;77(12):1933-1943. DOI: 10.1902/ jop.2006.060197.

3. Yu SK, Kim S, Kang SG, et al. Morphological assessment of the anterior loop of the mandibular canal in Koreans. Anat Cell Biol 2015;48(1):75-80. DOI: 10.5115/acb.2015.48.1.75.

4. Rosa MB, Sotto-Maior BS, Machado Vde C, et al. Retrospective study of the anterior loop of the inferior alveolar nerve and the incisive canal using cone beam computed tomography. Int J Oral Maxillofac Implants 2013;28(2):388-392. DOI: 10.11607/jomi.2648.

5. Solar P, Ulm CH, Frey G, et al. A classification of the intra osseous paths of the mental nerve. Int J Oral Maxillofac Implants 1994;9:339-344.

6. Apostolakis D, Brown JE. The anterior loop of the inferior alveolar nerve: prevalence, measurement of its length and a recommendation for interforaminal implant installation based on cone beam CT imaging. Clin Oral Implants Res 2012;23(9):1022-1030. DOI: 10.1111/j.1600-0501.2011.02261.x.

7. Kaya Y, Sencimen M, Sahin S, et al. Retrospective radiographic evaluation of the anterior loop of the mental nerve: comparison between panoramic radiography and spiral computerized tomography. Int J Oral Maxillofac Implants 2008;23(5):919-925.

8. Mclnnes MDF, Moher D, Thombs BD, et al. Preferred reporting items for a systematic review and meta-analysis of diagnostic test accuracy studies: the PRISMA-DTA statement. JAMA 2018;319(4):388-396. DOI: 10.1001/jama.2017.19163]. 
9. Vujanovic-Eskenazi A, Valero-James JM, Sánchez-Garcés MA, et al. A retrospective radiographic evaluation of the anterior loop of the mental nerve: comparison between panoramic radiography and cone beam computerized tomography. Med Oral Patol Oral Cir Bucal 2015;20:e239-e245. DOI: 10.4317/medoral.20026.

10. do Couto-Filho CE, de Moraes PH, Alonso MB, et al. Accuracy in the diagnosis of the mental nerve loop. A comparative study between panoramic radiography and cone beam computed tomography. Int J Morphol 2015;33(1):327-332. DOI: 10.4067/S071795022015000100051.

11. de Brito ACR, Nejaim Y, de Freitas DQ, et al. Panoramic radiographs underestimate extensions of the anterior loop and mandibular incisive canal. Imag Sci Dentis 2016;46(3):159-165. DOI: 10.5624/ isd.2016.46.3.159.

12. Kastala RK, David CM, Jayapal N. Momentousness of the mental loop: a comparative study. Contemp Clin Dent 2019;10(1):86-92. DOI: 10.4103/ccd.ccd_391_18.

13. Whiting PF, Rutjes AWS, Westwood ME, et al. QUADAS-2: a revised tool for the quality assessment of diagnostic accuracy studies. Ann Intern Med 2011;155(8):529-536. DOI: 10.7326/0003-4819-155-8-20111018000009.

14. Zamora J, Abraira V, Muriel A, et al. Meta-DiSc: a software for metaanalysis of test accuracy data. BMC Med Res Methodol 2006;6(1):31. DOI: 10.1186/1471-2288-6-31.

15. Zamora J, Muriel A, Abraira V, Meta-DiSc Statistical Methods. 2006 [ftp://ftp.hrc.es/pub/programas/metadisc/ MetaDisc_ StatisticalMethods.pdf]..

16. Wong SK, Patil PG. Measuring anterior loop length of the inferior alveolar nerve to estimate safe zone in implant planning: a CBCT study in a Malaysian population. J Prosthet Dent 2018;120(2):210-213. DOI: 10.1016/j.prosdent.2017.10.019.

17. Neiva RF, Gapski R, Wang HL. Morphometric analysis of implantrelated anatomy in Caucasian skulls. J Periodontol 2004;75(8):10611067. DOI: 10.1902/jop.2004.75.8.1061.

18. Padmanabhan H, Kumar AV, Shivashankar K. Incidence of neurosensory disturbance in mandibular implant surgery - a metaanalysis. J Indian Prosthodont Soc 2020;20(1):17-26. DOI: 10.4103/jips. jips_373_19.

19. Kheir MK, Sheikhi M. Assessment of the anterior loop of mental nerve in an Iranian population using cone beam computed tomography scan. Dent Res J 2017;14(6):418-422. DOI: 10.4103/1735-3327. 218566.

20. Bhargava A, Sehgal M, Gupta S, et al. Classification system on the selection of number of implants and superstructure design on the basis available vertical restorative space and interforaminal distance for implant supported mandibular overdenture. J Indian Prosthodont Soc 2016;16(2):131-135. DOI: 10.4103/0972-4052.176541.

21. Pradeep Christopher J, Marimuthu T, Krithika C, et al. Prevalence and measurement of anterior loop of the mandibular canal using CBCT: a cross sectional study. Clin Implant Dent Relat Res 2018;20(4):531-534. DOI: 10.1111/cid.12609.

22. Naitoh $M$, Nakahara $K$, Suenaga $Y$, et al. Comparison between cone beam and multislice computed tomography depicting mandibular neurovascular canal structures. Oral Surg Oral Med Oral Pathol Oral Radiol Endod 2010;109(1):e25-e31. DOI: 10.1016/j.tripleo.2009. 08.027.

23. Luangchana P, Pornprasertsuk-Damrongsri S, Kiattavorncharoen $S$, et al. Accuracy of linear measurements using cone beam computed tomography and panoramic radiography indental implant treatment planning. Int J Oral Maxillofac Implants 2015;30(6):1287-1294. DOI: 10.11607/jomi.4073.

24. Santana RR, Lozada J, Kleinman A, et al. Accuracy of cone beam computerized tomography and a three-dimensional stereo lithographic model in identifying the anterior loop of the mental nerve: a study on cadavers. J Oral Implantol 2012;38(6):668-676. DOI: 10.1563/AAID-JOI-D-11-00130.

25. Mardinger O, Chaushu G, Arensburg B, et al. Anterior loop of the mental canal: an anatomical-radiologic study. Implant Dent 2000;9(2):120-125. DOI: 10.1097/00008505-200009020-00003.

26. Kuzmanovic DV, Payne AG, Kieser JA, et al. Anterior loop of the mental nerve: a morphological and radiographic study. Clin Oral Implants Res 2003;14(4):464-471. DOI: 10.1034/j.1600-0501.2003. 00869.x.

27. Honest $\mathrm{H}$, Khan KS. Reporting of measures of accuracy in systematic reviews of diagnostic literature. BMC Health Serv Res 2002;2(1):4. DOI: 10.1186/1472-6963-2-4.

28. Mishra SK, Nahar R, Gaddale R, et al. Identification of anterior loop in different populations to avoid nerve injury during surgical procedures-a systematic review and meta-analysis. Oral Maxillofac Surg 2021;25(2):159-174. DOI: 10.1007/s10006-020-00915-x. 